\title{
O CORREDOR ECOLÓGICO COMO INSTRUMENTO DE GESTÃO AMBIENTAL PARA CONEXÃO DOS HABITATS FRAGMENTADOS
}

Laís Naiara Gonçalves dos Reis ${ }^{1}$

Josimar dos Reis Souza ${ }^{2}$

\begin{abstract}
RESUMO
A Legislação Ambiental brasileira tem contribuído para a formação de paisagens com habitats fragmentados, em função da não exigência da alocação das áreas de Reserva Legal em locais planejados e estratégicos para a promoção da conservação da biodiversidade. A falta de estudos e do planejamento e ordenamento das bacias hidrográficas não proporciona uma qualidade para que os órgãos ambientais interfiram no processo de Licenciamento Ambiental e julguem onde os proprietários devam alocar suas áreas de remanescentes da vegetação nativa. Neste contexto, o próprio Código Florestal brasileiro de 2012 prevê um instrumento para conectar esses habitats isolados, o Corredor Ecológico. Dessa forma, esse elemento se constitui como uma importante ferramenta para o planejamento ambiental, na busca por achar um modelo que contorne a fragmentação dos habitats privilegiando a qualidade das áreas de vegetação nativa em detrimento da quantidade. Esse artigo tem como finalidade reunir alguns conceitos sobre a Legislação Ambiental no sentido de conservação da biodiversidade, fragmentação dos habitats e Corredor Ecológico.
\end{abstract}

PALAVRAS-CHAVE: Fragmentação, habitats, Corredor Ecológico.

\section{ECOLOGICAL CORRIDOR AS A TOOL FOR ENVIRONMENTAL MANAGEMENT FOR CONNECTING FRAGMENTED HABITATS}

\section{ABSTRACT}

\footnotetext{
${ }^{1}$ Doutoranda em Geografia-UFU, Msc. em Geografia -UFU, Técnica de laboratório de Cartografia do Instituto de Geografia-UFU. E-mail: laisngr@ufu.br

${ }^{2}$ Mestrando em Geografia-UFU, Bacharel em Geografia-UFU. E-mail.
} 
The Brazilian Environmental Legislation has contributed to the formation of landscapes with fragmented habitats, depending on the requirement of not allocating the Legal Reserve areas in strategic and planned to promote biodiversity conservation sites. The lack of studies and the planning and management of river basins does not provide a quality so that environmental agencies interfering in the environmental licensing process and judge where the owners must allocate their areas of remnant native vegetation. In this context, the very Brazilian Forest Code of 2012 provides a tool to connect these isolated habitats, Ecological Corridor. Thus, this element constitutes an important tool for environmental planning, in seeking to find a model that circumvents the fragmentation of habitats favoring the quality of areas of native vegetation over quantity. This article aims to bring together some concepts on Environmental Legislation towards biodiversity conservation, habitat fragmentation and Ecological Corridor.

KEY-WORDS: Fragmentation, habitat, Ecological Corridor

\section{CORREDOR ECOLÓGICO COMO HERRAMIENTA DE GESTIÓN AMBIENTAL PARA CONECTAR HABITATS FRAGMENTADOS}

\section{RESUMEN}

La legislación ambiental brasileña ha contribuido a la formación de paisajes con hábitats fragmentados, en función de la exigencia de no asignar las áreas de Reserva Legal en estratégico y planificado para promover los sitios de conservación de la biodiversidad. La falta de estudios y la planificación y gestión de las cuencas hidrográficas no proporciona una calidad para que las agencias ambientales de interferir en el proceso de licenciamiento ambiental y juez del lugar donde los propietarios deben asignar sus áreas de vegetación nativa remanente. En este contexto, el Código Forestal Brasileño de 2012 muy proporciona una herramienta para conectar estos hábitats aislados, Corredor Ecológico. Por lo tanto, este elemento constituye una herramienta importante para la planificación del medio ambiente, en la búsqueda para encontrar un modelo que evita la fragmentación de los hábitats que favorecen la calidad de las zonas de vegetación nativa sobre la cantidad. Este artículo tiene como objetivo reunir a algunos conceptos de Legislación Ambiental hacia la conservación de la biodiversidad, la fragmentación del hábitat y el Corredor Ecológico.

PALABRAS-CLAVE: Fragmentación, hábitat, Corredor Ecológico.

\section{INTRODUÇÃO}

A conservação da biodiversidade é uma temática de relevância do século XXI, pois a sociedade contemporânea observa um cenário caótico de perda de biodiversidade. Os chamados países desenvolvidos desde a época da revolução industrial utilizaram demasiadamente seus recursos naturais, comprometendo-os para as gerações futuras. Muitas espécies foram extintas pelo mundo em prol do uso 
exaustivo dos recursos naturais, sendo o principal ameaçador de perda da biodiversidade, a fragmentação dos habitats. (PRIMACK, 1993)

Uma reportagem eletrônica "11 animais extintos há menos de 20 anos" do site TECMUNDO elucida que esse o problema é latente e que o planeta Terra continua perdendo espécies tanto da fauna quanto da flora. Os animais com respectiva data de extinção apresentados nessa lista são: tartaruga gigante de Galápagos (24 de junho de 2012), Rinoceronte negro do oeste (2011), Mergulhão de alaotra (2010), Foca monge das caraíbas (2008), Golfinho baiji (2006-2007), Po'ouli (2004), Mariana Mallard (2004), Íbex dos Pirineus (2000), Tigre-de-Java (1994), Pica-pau-bico-demarfim (1974), Canarian Oystercathcer (1994).

A partir do rompimento com a ciência positivista que admitia a natureza nela e por ela mesma, isto é externa as atividades humanas, a Geografia se responsabiliza em compreender a dialética da produção do espaço, admitindo que o Homem seja parte integrante do meio natural e condicionante deste, alterando-o e recebendo diretamente as implicações conduzidas sobre o espaço geográfico (CASSETI, 1991).

A análise do espaço geográfico permite compreender a relação do homem com a natureza, afirmando esta ideia de unidade dialética, onde as questões ambientais ganham relevância nas discussões sobre o ordenamento do território. Nesta perspectiva, a Geografia é afirmada enquanto parte da ciência responsável por integrar as partes do meio físico (Litosfera, Hidrosfera, Pedosfera, Biosfera) e apresentar a compreensão delas correlacionadas e dos processos dinâmicos de interação com o Homem (BERTRAND, 1968).

A vegetação nativa tem sido substituída, devido à prática da monocultura e demais usos em prol do agronegócio. Essa forma de apropriação do espaço é a maior responsável pelas causas de degradação dos ecossistemas como o isolamento geográfico dos habitats, por exemplo. Em que, a biodiversidade natural fica ameaçada por existir dificuldade de troca de genes e de competição por alimentos nos fragmentos florestais. Para Metzeger (1999), o processo de fragmentação dos habitats naturais é resultado das ações humanas, porque elas alteram a continuidade da paisagem, ocasionando mudanças na estrutura e na composição da mesma e consequentemente há perda da biodiversidade. 
Para Pirovani (2010), a fragmentação é caracterizada pela ruptura de uma unidade contínua, restando elementos menores que apresentam dinâmicas e processos ecológicos distintos da unidade original. Cada mancha (patch) se constitui como ecótopo da paisagem e o entorno dos fragmentos é chamado de matriz. Como estratégia para incrementar a conectividade dos habitats tem-se o corredor ecológico que serve como conector das unidades de conservação e/ou dos fragmentos importantes com a finalidade de manutenção da biodiversidade.

Esse trabalho tem como finalidade discutir alguns conceitos referentes à fragmentação dos habitats e corredores ecológicos. Esse artigo justifica-se pela necessidade de reunir um aporte teórico sobre esse assunto, uma vez que ele é contemporâneo às novas formas de gestão e conservação ambiental.

\section{DESENVOLVIMENTO}

\section{Aparato Legal Ambiental brasileiro e a contribuição para a formação de paisagens com habitats fragmentados}

A Constituição Federal (CF) de 1988 entende que as pessoas possuem direito ao meio ambiente ecologicamente equilibrado, portanto, prevê a criação e manutenção de espaços protegidos para esse fim em todo o território nacional. A palavra conservação só aparece uma vez na CF. No artigo 24, que diz que "compete à União, aos Estados e ao Distrito Federal Legislar corretamente sobre: VI - florestas, caça, pesca, fauna, conservação da natureza, defesa do solo e dos recursos naturais, proteção do meio ambiente e controle da poluição" (BRASIL, 1988).

Apenas uma menção à palavra conservação mostra o quão retrogrado é a política brasileira para conservação efetiva do Meio Ambiente, uma vez que, o exemplo da criação das Unidades de Conservação (UC) data desde o ano de 1872, com a criação do Parque Nacional de Yellowstone, nos Estados Unidos, que serviu de modelo para outros países como Canadá em 1985, Nova Zelândia em 1894, Austrália, África do Sul e México em 1898, Argentina em 1903, Chile em 1926, Equador em 1934, e Venezuela em 1937 (AGUIAR, 2013).

Os primeiros passos para estabelecer uma regra de uso dos recursos naturais no Brasil foram criados os Códigos de Águas, de Minas e Florestal Brasileiro em 1934, no Governo de Vargas em 1934. O primeiro Código Florestal (Decreto 
23.793/34) obrigou que os donos de terras a mantivesse $25 \%$ da área de seus imóveis com a cobertura de mata original. Entretanto, não fazia nenhuma menção do local de onde essa cobertura vegetal nativa deveria ser preservada.

Percebeu-se que a as áreas ao longo dos rios não estavam sendo preservadas, pois essas áreas eram utilizadas para diversos fins econômicos, o que desencadeou um processo de degradação ambiental e a perda da qualidade do recurso hídrico. Diante da ineficiência do Código Florestal de 1934, em 1965 surge outro Código Florestal que aponta as áreas de Preservação Permanente como as áreas ao entorno dos canais de drenagem e áreas com declividade superiores a $45^{\circ}$. Porém, nesse código não foi especificado onde deveria ser o local de alocação das reservas, o que permitiu que os agentes do espaço alocassem as áreas de preservação fora dos limites da bacia hidrográfica do empreendimento, por exemplo.

Buscando suprir algumas deficiências do Código Florestal de 1964 surge o Novo Código (LEI No 12.651, DE 25 DE MAIO DE 2012) que a respeito da localização das áreas de Reserva Legal dos imóveis rurais estabelece alguns critérios: necessário um plano de bacia hidrográfica, seguir o zoneamento Ecológico-Econômico e buscar a formação de corredores ecológicos com outra Reserva Legal, com Área de Preservação Permanente, com Unidade de Conservação ou com outra área legalmente protegida; devem ser alocados também onde seja detectada maior importância para a conservação da biodiversidade e em as áreas de maior fragilidade ambiental.

A Legislação Ambiental Brasileira, até o presente momento, não conseguiu cumprir com a garantia de conservação do meio ambiente e para com os processos de conservação ecológica. É possível afirmar que ela deu suporte para a construção de uma paisagem fragmentada, com fragmentos de vegetação ao longo do espaço sem ou quase nenhum planejamento caracterizando um alto nível de isolamento geográfico das manchas, sobretudo nas regiões onde o uso antrópico é consolidado, como nos biomas da Mata Atlântica e do Cerrado, por exemplo.

A partir desses pressupostos e com a crescente preocupação com a fragmentação dos habitats, a teoria da biogeografia das ilhas foi associada a essa 
paisagem fragmentada, onde os fragmentos de vegetação nativa estão cercados por demais usos que promovem o grau de isolamento destas áreas.

A Teoria de Biogeografia de Ilhas ajudou a refinar o pensamento das pessoas também sobre o isolamento de hábitat. Assim, tem sido previsto que as reservas que estão isoladas de outras áreas de hábitat por grandes extensões da paisagem degradada e hostil vão sustentar menos espécies do que aquelas mais próximas ao hábitat intacto. Isso ocorre porque reservas pouco isoladas são facilmente colonizadas por novas espécies e porque tal imigração gera contribuições genéticas e demográficas que podem reduzir as taxas de extinção local dentro da reserva (LAURENCE, 2008 apud DÔGE, s.d).

Dessa forma, os princípios básicos para os hábitats fragmentos na paisagem continental são:

1. Fragmentos maiores deverão suportar mais espécies que fragmentos menores;

2. O número de espécies deve diminuir com o aumento da distância do fragmento em relação a outros fragmentos

A paisagem dos habitats fragmentados em prol da substituição do uso por demais usos (agricultura, área urbana, rodovias, etc.) apresenta-se em vários mosaicos de habitats distintos, isto é, com forma, tamanho e densidade variados. A figura 01 mostra como o formato e organização desses fragmentos de vegetação nativa apresenta qualidades ambientais diferentes.

Figura 01. Forma e tamanho dos patches e qualidade ambiental

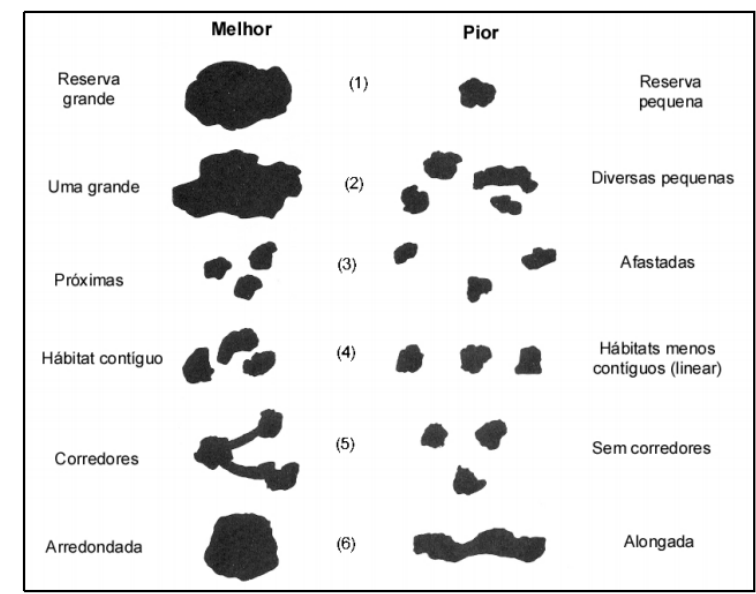

Fonte: BARROSO, 2002. 
A literatura referente à fragmentação dos habitas indica que fragmentos de vegetação nativa maiores, ou manchas próximas e com formatos mais arredondados são melhores ecologicamente do que as menores manchas mais distantes e formas irregulares. Existem formas para melhorar a dispersão entre as unidades de vegetação natural, como Corredores Ecológicos e tampões.

Walter (2004) aponta diferenças ao comparar os fragmentos de hábitats continentais com as ilhas oceânicas. Quadro 01.

\section{Quadro 01. Diferenças entre ilhas oceânicas e um fragmento de hábitat continental.}

\begin{tabular}{|c|c|c|}
\hline Propriedade ou processo & Ilha & Fragmento \\
\hline Geografia & $\begin{array}{l}\text { Pedaço isolado de terra cercado } \\
\text { por } 1000 \mathrm{~km} \text { de água em todas } \\
\text { as direções }\end{array}$ & $\begin{array}{l}\text { Parte de um habitat } \\
\text { anteriormente único ou unidade } \\
\text { de paisagem continental }\end{array}$ \\
\hline História & Originada há milhões de anos & Originada há décadas \\
\hline Dinâmica da área (tamanho) & Estável no tempo ecológico & $\begin{array}{l}\text { Redução e isolamento de outros } \\
\text { fragmentos de habitats } \\
\text { repentinos ou graduais }\end{array}$ \\
\hline Edge & Matriz de água salgada & $\begin{array}{l}\text { Um ou diversos tipos de habitat } \\
\text { cercam o fragmento }\end{array}$ \\
\hline Ecótono & Ausente & $\begin{array}{l}\text { Um ou muitos, depende da } \\
\text { composição da paisagem }\end{array}$ \\
\hline Predação & $\begin{array}{l}\text { Baixa: Maioria dos predadores } \\
\text { ausentes (mamíferos não } \\
\text { voadores, formigas carnívoras) }\end{array}$ & $\begin{array}{l}\text { Alta: a maioria dos predadores } \\
\text { está presente. (Fácil acesso a } \\
\text { partir da borda) }\end{array}$ \\
\hline Estabilidade & $\begin{array}{c}\text { Alta, exceto após evento de } \\
\text { distúrbio (de origem externa ou } \\
\text { vulcânica) }\end{array}$ & $\begin{array}{l}\text { Baixa devido à redução do } \\
\text { tamanho das populações: } \\
\text { espécies grandes, raras, } \\
\text { especialistas tendem a } \\
\text { desaparecer do fragmento }\end{array}$ \\
\hline Evolução & Táxons endêmicos & $\begin{array}{l}\text { Fragmentos podem conter } \\
\text { populações viáveis ou não } \\
\text { viáveis de táxons continentais }\end{array}$ \\
\hline Invasibilidade & $\begin{array}{c}\text { Negligenciável, exceto se } \\
\text { suportado pelo Homem, barreira } \\
\text { de água altamente protetora }\end{array}$ & $\begin{array}{c}\text { Alta devido ao efeito de borda e } \\
\text { a proximidade da matriz } \\
\text { adjacente }\end{array}$ \\
\hline Robustez & $\begin{array}{c}\text { Alta: suporta toda sua } \\
\text { diversidade em longo prazo }\end{array}$ & $\begin{array}{c}\text { Baixa: não pode suportar } \\
\text { animais com ampla homer } \\
\text { angers, perda da qualidade de } \\
\text { hábitat devido ao efeito de borda }\end{array}$ \\
\hline Sucessão & $\begin{array}{l}\text { Estágios normais dentro do } \\
\text { ecossistema insular }\end{array}$ & $\begin{array}{l}\text { Sucessão impedida: áreas de } \\
\text { floresta original irão desaparecer }\end{array}$ \\
\hline
\end{tabular}

Fonte: Adaptado de WALTER (2004)

Gestão e ordenamento de bacias hidrográficas para conservação da biodiversidade: Corredor Ecológico 
O corredor ecológico enquanto um conector das unidades de conservação ou dos fragmentos pode e deve ser utilizado para manutenção da biodiversidade, já que conforme Sodhi (1999) o mesmo pode formar uma rede de habitats que possibilitariam a conexão genética das populações e aumento da importância do Planejamento Ambiental e Ecologia da Paisagem.

Existem diversas iniciativas de corredores ecológicos no Brasil; por exemplo, o Corredor Central da Mata Atlântica, o Corredor Central da Amazônia, ambos implantados pelo Projeto de corredores ecológicos do MMA e PPG-7; o Corredor do Amapá, sob iniciativa do Governo do Amapá e Conservação Internacional; o Corredor Emas-Taquari, no Cerrado criado pela Conservação Internacional e parceiros locais; o corredor da Serra do Mar implantado pelo Fundo de Parceria para Ecossistemas Críticos; o Corredor do Nordeste, criado pelo centro de Pesquisas Ambientais do Nordeste (CEPAN) e pela conservação Internacional; além dos corredores já conhecidos, criados pelo IBAMA. (ANJOS, H.O, 2008)

De acordo com o Sistema Nacional de Unidades de Conservação da natureza (SNUC Lei 9.985 de 18 de julho de 2000), o Corredor Ecológico é um instrumento de gestão e ordenamento territorial que visa manter os processos ecológicos. Isto é, permitindo a dispersão de espécies, recolonização de áreas degradadas, fluxo gênico, viabilidade de populações que demandam mais do que o território de uma unidade de conservação e ou fragmento para sobreviver.

Existem Corredores para a conservação de espécies individuais e para integração de comunidades. Um corredor ecológico pode ser entendido como a conectividade entre os fragmentos florestais, que viabilize a locomoção da fauna e a troca de genes da flora. Diferentes tipos de elementos da paisagem podem aumentar a conectividade entre os fragmentos florestais. Muitos são os elementos que podem servir como corredor e não são explícitos (cercas vivas, vegetação ao lado das rodovias e estradas).

As matas ciliares (Buffering Riparian Zones) são estratégicas para compor os corredores ecológicos. "Riparian corridors are made up of vegetation growing adjacent to creeks and rivers that are sometimes retained in human dominated landscape." (HILTY, 2006). Essas áreas são áreas protegidas por leis, portanto, são fundamentais para se constituírem como elementos de um Corredor Ecológico, sobretudo para o 
Cerrado, que se configurou como fronteira agrícola desde a década de 70 e apresenta uma matriz de antropização consolidada.

A conservação dos leitos dos rios em conjunto com as matas ciliares, possui uma boa conectividade com diferentes áreas não somente para os animais aquáticos, mas como também para animais que buscam abrigos ou comida nesses habitats, tais como borboletas, pássaros e outros.

Quanto à tipologia dos corredores ecológicos, a literatura indica duas classificações: contínuos e não contínuos. O Corredor do tipo contínuo atende um maior número de elementos da fauna, com processo de reabilitação mais eficiente. $\mathrm{O}$ Corredor não contínuo é representado por ilhas de vegetação, criadas estrategicamente, porém o processo de reabilitação é menor do que o primeiro. (LOUZADA, 2010)

Corredores Lineares e contínuos permitem a locomoção de animais maiores.

Com base em VÂNIA KORMAN, os corredores ecológicos são usados como estratégia conservacionista desde o início do século $\mathrm{XX}$, principalmente para aves. A referida autora cita trabalho realizado em Queensland, Austrália, que sugere que remanescentes lineares, florísticamente diversificados e apresentando pelo menos de 30 a 40 metros de largura, podem funcionar como habitat e, provavelmente, como corredores de movimento para a maioria dos mamíferos arbóreos daquela região. (VALERI et al, 2004)

Valeri et al. (2004) mostram os critérios adotados para estabelecer o corredor ecológico em São Paulo, para possibilitar o acesso da fauna aos fragmentos florestais.

Foi implantado um corredor ecológico com 30 metros de largura e 600 metros de comprimento, interligando-o a uma área de preservação permanente ao redor de uma nascente, beneficiária do Córrego Jaboticabal. A implantação do corredor ocorreu em 26 de outubro de 2000, com o plantio de 3.519 mudas de110 espécies arbóreas nativas, cumprindo as exigências da Resolução $n^{\circ} 21$ da Secretaria do Meio Ambiente do Estado de São Paulo, publicada no Diário Oficial em 23/11/2001. (VALERI et al, 2004)

Os corredores ecológicos são importantes para o planejamento ambiental, pois ajudam a conciliar o desenvolvimento urbano com as atividades econômicas no espaço, buscando contornar as consequências da fragmentação dos habitats nessa área e, assim, conectá-los, proporcionando o fluxo de biodiversidade. (SILVA et al., 2011) 
Todas essas estratégias para conservação da biodiversidade devem ser pensadas dentro do planejamento ambiental. Franco (2001) discute que o planejamento ambiental deve partir das bases naturais para a sustentação da vida e das suas relações ecossistêmicas em um determinado território. Portanto, o planejamento ambiental deveria visar à diminuição dos gastos de energia que o sustenta, o seu grau de entropia, assim como os riscos e impactos ambientais, sem prejudicar ou suprimir outros seres da cadeia ecológica da qual o homem faz parte, mantendo a biodiversidade dos ecossistemas.

O diagnóstico da biodiversidade é importante para planejar um cenário com o propósito de evitar a extinção das espécies, a perda da variabilidade genética e a destruição de comunidades biológicas. Outro importante fator é o conhecimento das espécies-chaves, que devem ser preservadas para que todo um ecossistema seja mantido em equilíbrio.

Outra importante decisão para conservação da biodiversidade poderia ser conservada por um modelo ideal de manutenção de grandes unidades de conservação, que dispersas geograficamente possibilitem a manutenção da população mínima viável (PMV) em longo prazo e representativas da biota. As quais seriam reservas biológicas protegidas por lei, como Parques Estaduais ou Nacionais. (SANTOS, 2002). Os planejadores do espaço devem pensar em áreas prioritárias para conservação dos habitats, inclusive no processo de criação de novas unidades de conservação (UC).

Além dos outros aspectos discutidos nesse texto, para fazer o planejamento dos corredores ecológicos em uma bacia hidrográfica, também é preciso realizar a avaliação das matrizes dos fragmentos, isto é, avaliar o tipo de uso da terra e manejo ao entorno das áreas destes habitats. A principal análise das matrizes em Ecologia de Paisagens está ligada com o quesito da permeabilidade dessas regiões, ou seja, no grau de facilidade de deslocamento dos organismos para outro fragmento.

A permeabilidade da matriz como um todo pode ser estimada pela densidade de pontos de ligação e pelo grau de resistência das unidades da paisagem aos fluxos biológicos. Os pontos de ligação constituem pequenas áreas de habitat dispersas na matriz. Estes pontos podem ter um papel importante no movimento de algumas espécies ou na persistência, numa paisagem 
fragmentada, de espécies que não carecem de grandes espaços de habitat para se desenvolverem (WHITCOMB et al., 1976 apud JUVANHOL, 2011).

Para isso, as unidades da paisagem (UP) de uma bacia devem ser mapeadas. Estas UP's são formadas por uma matriz composta por um grupo de ecossistemas dominantes, contendo manchas ou fragmentos de outros ecossistemas, arranjados em padrões variáveis, conectados entre si ou isolados. As conexões entre os fragmentos são denominadas corredores ecológicos, pois funcionam como meio de passagem para a biota que ocupa os fragmentos. Cada unidade da paisagem possui estrutura, condições ambientais, funcionamento e percepções próprios e inerentes a sua área, disposição espacial e/ou forma. (FORMAN, 1995, apud SANTOS, 2002).

Inseridas na matriz, encontram-se as manchas de ecossistemas originais ou deles derivados que funcionam como habitats naturais para a biota regional. As dimensões destas manchas, suas formas e a disposição espacial de seu conjunto determinam as suas qualidades como habitat para a biota. (COLLINGE, 1996, apud SANTOS, 2002)

A conservação das populações biológicas está diretamente ligada à estrutura da paisagem, pois ela influi na dinâmica das populações. Nas áreas urbanizadas, principalmente, a atividade humana transformou e ainda transforma a paisagem original em um mosaico fragmentado de habitats. Sendo assim, os Corredores Ecológicos são considerados formas de resistência para esse modelo produtor de paisagens fragmentadas, e são apontados como um novo instrumento de gestão e ordenamento da paisagem.

\section{CONCLUSÃO}

O histórico de criação das Unidades de Conservação no país já possui mais de sessenta anos, observa-se que as áreas criadas não são o suficiente para impedir a ameaça de extinção de algumas espécies da fauna e da flora do Brasil, o que indica falha no processo de criação dessas áreas e gestão, uma vez que as políticas ambientais corroboram para a criação de uma paisagem de habitats fragmentados. 
$\mathrm{O}$ isolamento e a perda de habitats são as principais causas de perda de diversidade biológica do mundo. É preciso antes de utilizar instrumentos que possam incrementar a conectividade dos habitats, a criação de uma Legislação ambiental que valorize a qualidade em detrimento da quantidade de áreas verdes, determinando o local onde as áreas de reserva legal devam ser alocadas.

E preciso que as propostas de Corredores Ecológicas passem a ter obrigatoriedade perante a Lei. O Corredor Ecológico é uma importante ferramenta de gestão e ordenamento das Bacias Hidrográficas, pois melhoram a conectividade entre os fragmentos florestais e permite a locomoção da fauna e troca de genes da flora, garantindo a manutenção da biodiversidade.

\section{REFERÊNCIAS}

AGUIAR et al. Áreas naturais protegidas: um breve histórico do surgimento dos Parques Nacionais e das Reservas Extrativistas. Disponível em:< http://www.revistas.una.ac.cr/index.php/geografica/article/viewFile/5396/5228> Acessado em junho de 2014.

ANJOS, H. O. Avaliação de riscos ambientais na delimitação de áreas potenciais para corredores ecológicos na sub-bacia hidrográfica do rio das Almas-GO. Disponível em:< http://repositorio.unb.br/bitstream/10482/1734/1/Tese\%20-\%20250109.pdf> Acessado em março de 2014.

BARROSO.Teoria de Biogeografia de llhas. Disponível em:< http://ucbweb2.castelobranco.br/webcaf/arquivos/12787/4787/Biogegrafia_de_ILhas.pdf> Acessado em janeiro de 2014.

BERTRAND, G. Paysage et géographie physique globale: esquisse méthodologique. Revue géographique des Pyrénées et sud-ouest, v. 39, n. 1, p. 249-272, 1968.

BRASIL. Constituição da República Federativa do Brasil de 1988. Disponível em:< http://www.planalto.gov.br/ccivil_03/constituicao/constituicao.htm> Acessado em junho de 2014.

CASSETI, V. Geomorfologia, 1991. Disponível em:< www.funape.org.br/geomorfologia./> Acessado em março de 2014.

DÔGE, J. Biogeografia aplicada a Edcologia de Paisagens. Disponível em:< http://ecopaisagem. wikispaces.com/Biogeografia+aplicada+a+Paisagens > Acessado em janeiro de 2014.

FRANCO, M. A. de R. Planejamento ambiental apara a cidade sustentável. São Paulo: Annablume: Fapesp, 2001.

HILTY, J.A; LIDICKER, W. Z; MERENLENDER, A. Corridor Ecology: The Science and practice of Linking Landcapes for Biodiversity Conservation. (2006) pp. 5-323 
JUVANHOL, R. S. Análise Espacial de Fragmentos Florestais no Corredor Ecológico entre os Parques Estaduais de Forno Grande e Pedra Azul, ES. Disponível em:<

http://www.corredoresecologicos.es.gov.br/publicacoes/TCC2011-RONIE.pdf > Acessado em fevereiro de 2014.

LAURANCE, W.F. Theory meets reality: How habitat fragmentation research has transcended island biogeographic theory. Biological Conservation , 2008. 141: 1731-174

LOUZADA, F. L. R. O. Proposta de Corredor Ecológico para interligação dos Parques Estaduais do Forno Grande e Pedra Azul, ES, utilizando geotecnologias. Disponível em:< http://www.mundogeomatica.com.br/TesesMonografias/Tese_Site/Tese_Franciane.pdf > Acesso em maio de 2014.

METZGER, J.P. Estrutura da Paisagem e Fragmentação: Análise Bibliográfica. Academia Brasileira de Ciências. v.71, n. 3-I, 445-463, Rio de Janeiro.1999.

PIROVANI, D. B. Fragmentação Florestal , dinâmica e Ecologia de Paisagem na bacia hidrográfica do Rio Itapmerim. Diponível em :<

http://www.mundogeomatica.com.br/TesesMonografias/Tese_Site/Tese_\%20Daiani.pdf > Acessado em junho de 2014.

PRIMACK; R. B; RODRIGUES, E. Biologia da Conservação. Londrina, 2001, p.325.

SANTOS, J. S. M. Análise da paisagem de um Corredor Ecológico na Serra da Mantiqueira. Disponível em:< http://www.obt.inpe.br/pgsere/Santos-J-S-M-2002/publicacao.pdf> Acessado em janeiro de 2014.

SILVA et al. Uma proposta de Corredor Ecológico para o Município de Uberlândia. Disponível em:< http://www.observatorium.ig.ufu.br/pdfs/3edicao/n7/8.pdf > Acessado em maio de 2014.

TECMUNDO. Reportagem Eletrônica: 11 animais extintos em 20 anos. Disponível em:< http://www.tecmundo.com.br/ciencia/26199-11-animais-extintos-ha-menos-de-20-anos.htm: Acessado em junho de 2014.

VALERI, S. V,. SENÔ, M. A.A. A Importância dos Corredores Ecológicos para a fauna e a sustentabilidade de remanescentes florestais. Disponível em:<

http://www.clienteg3w.com.br/celiarusso/site/corredores_ecologicos.pdf> Acessado em março de 2014.

Walter, H. S.The mismeasure of islands: implications for biogeog raphical theory and the conservation of nature. Journal of Biogeography, 2004. pp. 177-197. 